
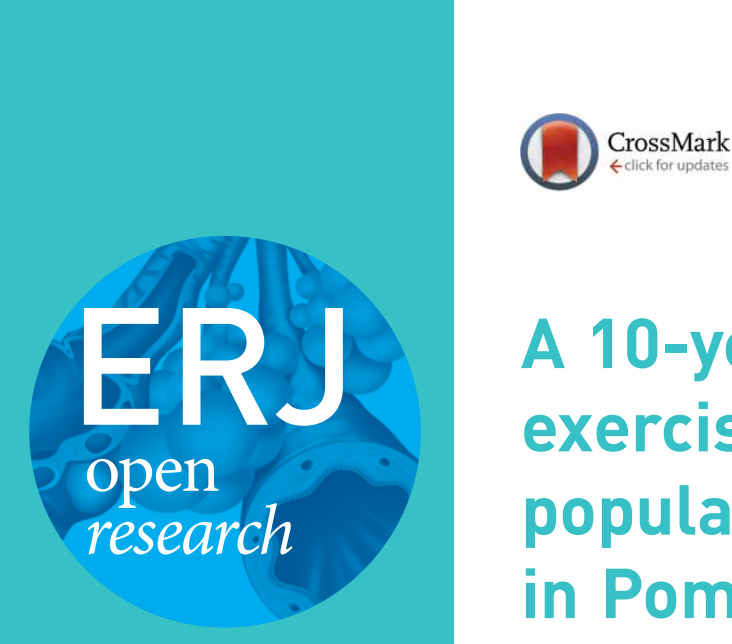

\title{
A 10-year follow-up of key gas exchange exercise parameters in a general population: results of the Study of Health in Pomerania
}

\author{
Beate Stubbe (10 ${ }^{1,5}$, Till Ittermann (10 ${ }^{2,5}$, Sabine Kaczmarek (10) ${ }^{1}$, Anne Obst (10) \\ Martin Bahls $\mathbb{1}^{1}$, Tom Bollmann $\mathbb{1}^{3}$, Sven Gläser $\mathbb{1}^{4}$, Henry Völzke $\mathbb{1}^{2}$, \\ Marcus Dörr (101 and Ralf Ewert (10 ${ }^{1}$
}

Affiliations: ${ }^{1}$ Cardiology, Pneumology, Infectious Diseases and Intensive Care Medicine, Dept of Internal Medicine B, University Hospital Greifswald, Greifswald, Germany. ${ }^{2}$ Institute for Community Medicine, SHIP/ Clinical-Epidemiological Research, University of Greifswald, Greifswald, Germany. ${ }^{3}$ Pneumologie, Helios Hanse Hospital Stralsund, Stralsund, Germany. ${ }^{4}$ Pneumologie, Vivantes Hospital Berlin-Neukölln, Berlin, Germany. ${ }^{5}$ These authors contributed equally.

Correspondence: Beate Stubbe, Cardiology, Pneumology, Infectious Diseases and Intensive Care Medicine, Dept of Internal Medicine B, University Hospital Greifswald, Ferdinand-Sauerbruch-Straße, 17475 Greifswald, Germany. E-mail: beate.stubbelamed.uni-greifswald.de

\section{ABSTRACT}

Background: Cardiopulmonary exercise testing (CPET) is a frequently used method for the evaluation of the cardiorespiratory system. The prognostic relevance of the measured parameters is commonly known. Longitudinal data on cardiorespiratory fitness in a large sample of well-characterised healthy volunteers are rare in the literature.

Methods: CPET data of 615 healthy individuals who voluntarily took part in the Study of Health in Pomerania (SHIP) at three different measurement times were analysed. The median observation time was 10.5 years. The age range was $25-85$ years.

Results: Over the observed timeframe and with increasing age, a decline in maximum power, peak oxygen uptake $\left(V_{\mathrm{O}_{2} \text { peak }}^{\prime}\right)$ and oxygen uptake at anaerobic threshold $\left(V_{\mathrm{O}_{2}}^{\prime} @ \mathrm{AT}\right)$ was detectable. This decline was aggravated with increasing age. For the minute ventilation $\left(V_{\mathrm{E}}^{\prime}\right) /$ carbon dioxide production $\left(V^{\prime} \mathrm{CO}_{2}\right)$ slope, an increase was measured in individuals aged $\geqslant 50$ years only.

Conclusion: The present study affirms the decrease in aerobic capacity with increasing age in a selected, well-characterised, healthy study sample, which seems to be less pronounced in females.

@ERSpublications

A 10-year follow-up of the Study of Health in Pomerania affirms the decrease in aerobic capacity with increasing age in a selected, well-characterised, healthy study sample, which seems to be less pronounced in females https://bit.ly/3pIJmpM

Cite this article as: Stubbe B, Ittermann T, Kaczmarek S, et al. A 10-year follow-up of key gas exchange exercise parameters in a general population: results of the Study of Health in Pomerania. ERJ Open Res 2021; 7: 00350-2020 [https://doi.org/10.1183/23120541.00350-2020].

Copyright $\odot$ ERS 2021. This article is open access and distributed under the terms of the Creative Commons Attribution Non-Commercial Licence 4.0. 


\section{Introduction}

Cardiopulmonary exercise testing (CPET) is used in clinical practice to measure pulmonary, cardiac and musculoskeletal function to assess the severity of an existing disorder. Several parameters of cardiorespiratory fitness assessed by CPET (e.g. peak oxygen uptake $\left(V^{\prime}{ }_{2}\right.$ peak $)$, oxygen uptake at anaerobic threshold ( $\left.V_{\mathrm{O}_{2}}^{\prime} @ \mathrm{AT}\right)$, oxygen pulse and breathing efficiency expressed as the minute ventilation $\left(V_{\mathrm{E}}^{\prime}\right) /$ carbon dioxide production $\left(V^{\prime} \mathrm{CO}_{2}\right)$ slope) are known to have prognostic relevance. Hence, they are used for risk stratification in patients with cardiorespiratory diseases [1].

In addition to its clinical application, CPET is used in epidemiological studies. For example, high levels of cardiorespiratory fitness are related to a lower risk of mortality [2-4] and cardiovascular diseases [5, 6]. The Norwegian HUNT study demonstrated a cross-sectional association between objectively measured $V^{\prime} \mathrm{O}_{2}$ peak and levels of conventional cardiovascular risk factors in volunteers aged 20-90 years (2368 males and 2263 females) [7]. Further cross-sectional studies confirmed age and sex as important determinants of cardiorespiratory fitness [8-10], and consistently confirmed higher age to be related to lower levels of aerobic fitness. Another study in 751 males and females aged $20-85$ years reported a linear decrease $(8 \%$ per decade) in $V^{\prime}{ }_{\mathrm{O}_{2} \text { peak }}$ for both sexes, starting from the age of 30 years [11]. Likewise, a linear decrease in aerobic capacity $\left(V^{\prime} \mathrm{O}_{2}\right.$ peak and $\left.V_{\mathrm{O}_{2}} @ A T\right)$ was seen in 298 males and females aged 55-86 years [12]. In a much larger study that analysed data of 4494 volunteers, a decline in $V^{\prime}{ }_{\mathrm{O}_{2} \text { peak }}$ of almost $50 \%$ was found for both sexes in a younger age group (20-29 years) compared with an older age group (70-79 years), i.e. a decline of $10 \%$ per decade [13]. The decline in aerobic capacity of $10 \%$ per decade was finally confirmed in a meta-analysis of 17 cross-sectional studies [14]. Another meta-analysis of 242 studies with 13828 male subjects [15] showed no significant difference in the decrease of $V^{\prime}{ }_{\mathrm{O}_{2} \text { peak }}$ over time depending on age or physical activity. In contrast, a meta-analysis of 109 studies with 4484 female subjects found a greater decrease in aerobic capacity with age in physically active females [16]. The decrease in $V^{\prime}{ }_{\mathrm{O}_{2} \text { peak }}$ and oxygen pulse with higher age was also confirmed in a further meta-analysis [17].

Smaller longitudinal studies confirmed the finding of a decrease in aerobic capacity with increasing age (overview in HaWkins and Wiswell [14]). For example, in one study that initially included 441 volunteers aged 55-85 years, only 115 were examined after 10 years and only data from 62 were included in the analyses. Among this very selected study sample, however, $V_{\mathrm{O}_{2} \text { peak }}^{\prime}$ decreased by $14 \%$ in males compared with only $7 \%$ in females [18]. Furthermore, three population-based longitudinal studies (375 females and 435 males, age 21-87 years, median observation 7.9 years [19]; 339 females and 253 males, age 53-87 years, median observation 6.3 years [20]; 579 males, age 42-60 years, median observation 11 years [21]) demonstrated a decrease of $V^{\prime} \mathrm{O}_{2}$ peak of $\sim 10 \%$ per decade for both sexes.

In summary, it can be concluded that in both cross-sectional and longitudinal studies an age-related decrease in aerobic capacity has been consistently observed for both sexes. However, available data from longitudinal studies in volunteers were often limited by small sample sizes (mostly $\mathrm{n}<100$ ). Up to now, only two population-based longitudinal larger studies with multiple measurement times are available [19, 20]. Only FLEG et al. [19] report data over a wide age range (21-87 years), obtained between 1978 and 1998 as part of the Baltimore Longitudinal Study of Aging.

The aim of our study was to analyse the course of aerobic capacity in a large sample of the population-based Study of Health in Pomerania (SHIP) between 2002 and 2019, under consideration of a wide age range and at three different measurement times.

\section{Methods}

\section{Description of the samples}

SHIP is a population-based study, conducted in a region in north-eastern Germany (West Pomerania) with about 213000 inhabitants. The methodological approaches have already been described in detail previously $[22,23]$. In brief, the first examination (SHIP-0) included 4308 subjects (response rate $68.8 \%$ ) around the cities of Greifswald and Stralsund, and was carried out between 1997 and 2001. Between 2002 and 2006, still-living participants were invited to the first follow-up examination (SHIP-1) and 3300 (corresponding to a response rate of $83.6 \%$ ) could be examined. At this time-point, both pulmonary function testing and CPET were offered for the first time on a voluntary basis. A total of 1703 (51.6\%) subjects participated in CPET. The second follow-up examination (SHIP-2) was conducted between 2008 and 2012, with 2333 subjects (response rate 67.4\%) being included. Among those, a total of 1442 (61.8\%) subjects volunteered to participate in CPET. During the third follow-up examination (SHIP-3) a total of 1718 subjects (response rate 39.9\%) were examined between 2014 and 2019, 1066 (62.0\%) of whom received $\mathrm{CPET}$.

Data of 615 subjects (317 males and 298 females) who participated in CPET at all three examination points were available for our analyses (figure 1). The median observation time was 10.5 years. 


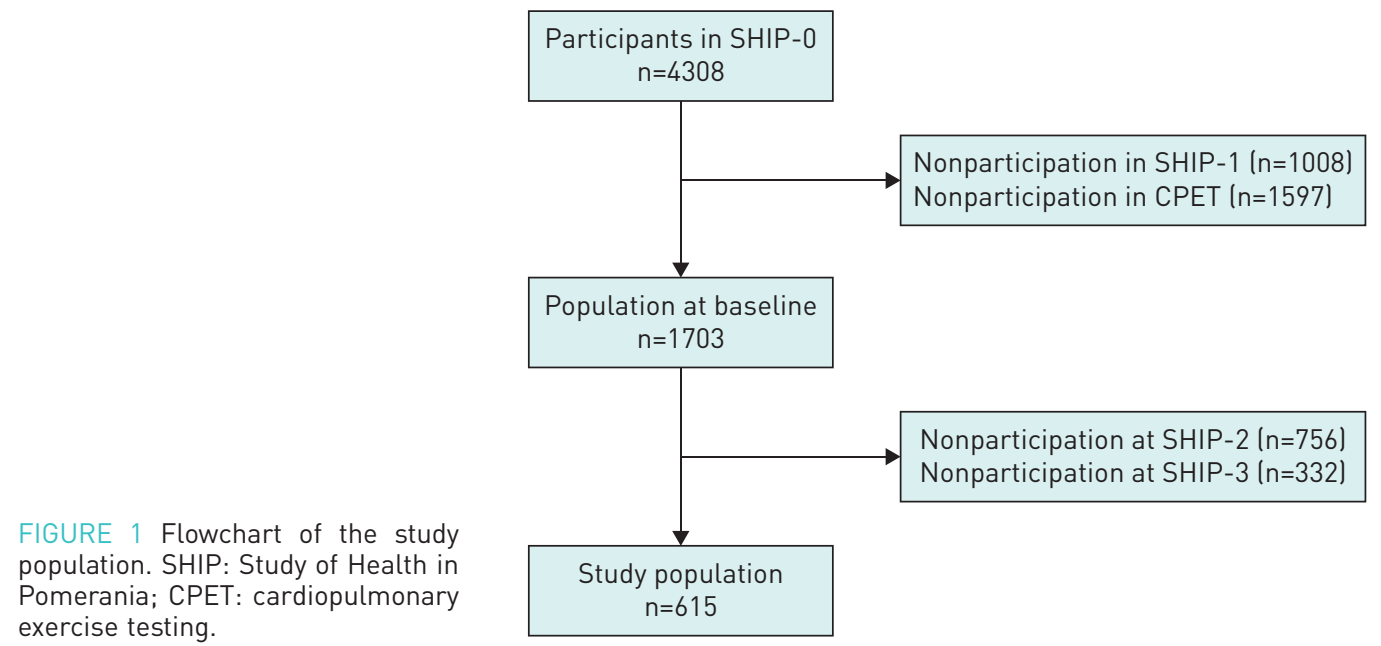

The study conformed to the principles of the Declaration of Helsinki as reflected by the approval by the Ethics Committee of the University of Greifswald.

\section{Cardiopulmonary exercise testing}

The method used in SHIP for CPET has been described in detail previously [24, 25]. In brief, symptom-limited CPET was performed according to a modified Jones protocol using a calibrated electromagnetically braked cycle ergometer (Ergoselect 100; Ergoline, Bitz, Germany). Gas exchanges were measured breath-by-breath using an Oxycon Pro with a Rudolf mask (Jäger/Viasys Healthcare, Hoechberg, Germany).

In SHIP-1 and SHIP-2, the assessment of $V_{\mathrm{O}_{2} \text { peak, }}^{\prime} V_{\mathrm{O}_{2}}^{\prime} @ \mathrm{AT}$, oxygen pulse and $V_{\mathrm{E}}^{\prime} / V^{\prime} \mathrm{CO}_{2}$ slope was based on the printout, while in SHIP-3 these parameters were assessed using a computer-aided algorithm. Therefore, a "correction formula" had to be applied, which was developed based on a random sample of SHIP-1 $(n=446)$ and SHIP-2 $(n=606)$ by comparing the values derived by the original printout-based method with those calculated by a double determination using the computer-assisted method. Differences for $V^{\prime} \mathrm{O}_{2} @ \mathrm{AT}$ and $V_{\mathrm{E}}^{\prime} / V^{\prime} \mathrm{CO}_{2}$ slope were calculated by linear regression and applied to the data for correction: $V_{\mathrm{O}_{2}}^{\prime} @ \mathrm{AT}$ : SHIP-1 149.04+0.83 $\times V_{\mathrm{O}_{2}}^{\prime} @ \mathrm{AT}, \mathrm{SHIP}-2104.67+0.93 \times V_{\mathrm{O}_{2}}^{\prime} @ \mathrm{AT} ; V_{\mathrm{E}}^{\prime} / V^{\prime} \mathrm{CO}_{2}$ slope: SHIP-1 5.11+0.78 $\times V^{\prime}{ }_{\mathrm{E}} / V^{\prime} \mathrm{CO}_{2}$ slope, SHIP-2 $-0.29+0.93 \times V_{\mathrm{E}}^{\prime} / V_{\mathrm{CO}_{2}}^{\prime}$ slope.

\section{Statistical analyses}

To describe differences between participants and nonparticipants at the follow-up examinations, we compared these two groups by median (interquartile range (IQR)) for continuous baseline data and by absolute number (percentage) for categorical baseline data. The progression of continuous variables over the three time-points (i.e. SHIP-1, SHIP-2 and SHIP-3) is described by box plots (median, IQR and minimum-maximum range) and the progression of categorical variables is given by bar plots. Differences in continuous variables between SHIP-1 and SHIP-3 were evaluated by the t-test for paired data (continuous data) or McNemar's test (categorical data). Stratified by sex, we associated age with 5- and

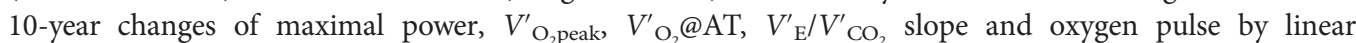
regression models. For $V^{\prime} \mathrm{O}_{2}$ peak we furthermore calculated expected values at the 5- and 10-year follow-up using the median formulas described by GLÄsER et al. [25]. The expected $V^{\prime} \mathrm{O}_{2}$ peak values were calculated by dividing the coefficient for age from the reported formulas multiplied by the respective individual follow-up time from the $V^{\prime} \mathrm{O}_{2}$ peak value observed in SHIP-1, e.g. in males the formula for median $V^{\prime} \mathrm{O}_{2}$ peak from GLäSER et al. [25] was $V_{\mathrm{O}_{2} \text { peak }}^{\prime}\left(\mathrm{mL} \cdot \mathrm{min}^{-1}\right)=254.761-22.6925 \times$ age $\quad$ (years)+17.2463 $\times$ height $(\mathrm{cm})+4.4114 \times$ weight $(\mathrm{kg})$, assuming that in males $V_{\mathrm{O}_{2} \text { peak }}^{\prime}$ decreases by $22.6925 \mathrm{~mL} \cdot \mathrm{min}^{-1} \cdot$ year $^{-1}$. For

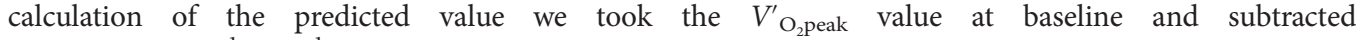
$22.6925 \mathrm{~mL} \cdot \mathrm{min}^{-1} \cdot \mathrm{year}^{-1}$ of follow-up. The observed values in SHIP-2 and SHIP-3 were associated with the expected values in SHIP-2 and SHIP-3, respectively, and the $\mathrm{R}^{2}$-values were calculated. These calculations were conducted in the total population as well as sex stratified. A p-value $<0.05$ was considered as statistically significant in all calculations. Analyses were performed with Stata version 16.1 (StataCorp, College Station, TX, USA). 


\section{Results}

In table 1 we compare the baseline characteristics of the 615 individuals who participated at all three time-points with the baseline characteristics of the 1087 individuals who did not participate at all three time-points. Individuals participating at all three time-points were slightly younger, were more often male but less often smokers, had a lower body mass index (BMI), and less often had type 2 diabetes mellitus, hypertension, stroke and myocardial infarction than individuals not available at all three time-points. Baseline markers of lung function and CPET tended to be better in individuals attending CPET examinations at all three time-points.

Of the 615 individuals available at all three time-points, 141 individuals were 25-39 years old at baseline, 328 individuals were $40-59$ years old and 146 individuals were 60-85 years old. The percentage of current smokers decreased from $20.5 \%$ at baseline (SHIP-1) to $14.8 \%$ and $13.4 \%$ at the first (5-year; SHIP-2) and second (10-year; SHIP-3) follow-ups, respectively (figure $2 \mathrm{a}$ and b). The decrease from baseline to the first follow-up was significant $(\mathrm{p}<0.001)$, but not the decrease from the first to the second follow-up $(\mathrm{p}=0.108)$. The median BMI increased from 25.9 to 27.0 and $27.3 \mathrm{~kg} \cdot \mathrm{m}^{-2}$ at the first and second follow-ups, respectively (figure $2 \mathrm{c}$ and $\mathrm{d}$ ). Increases from baseline to the first follow-up and between the first and the second follow-up were statistically significant $(\mathrm{p}<0.001)$. The prevalence of type 2 diabetes increased from $5.0 \%$ at baseline to $7.6 \%(\mathrm{p}<0.001)$ and $9.1 \%(\mathrm{p}=0.035)$ at the first and second follow-ups, respectively. Likewise, the prevalence of arterial hypertension increased from $39.2 \%$ to $50.2 \%(p<0.001)$ and $63.1 \%$ $(\mathrm{p}<0.001)$ at the first and second follow-ups, respectively. The prevalence of myocardial infarction (baseline 1.6\%; first follow-up 2.4\% ( $\mathrm{p}=0.063)$; second follow-up 3.4\% ( $\mathrm{p}=0.109)$ ) and stroke (baseline $0.8 \%$; first follow-up $1.6 \%(\mathrm{p}=0.063)$; second follow-up $3.3 \%(\mathrm{p}=0.007)$ ) increased moderately during follow-up.

While in individuals aged $<60$ years no decrease in the maximum power was observed until the second follow-up, there was a significant decrease in individuals aged $\geqslant 60$ years (figure 3 , and tables 2 and 3 ). Overall, the mean maximum power decreased until the first follow-up from 165 to $160 \mathrm{~W}$ and afterwards increased again to $165 \mathrm{~W}$ during the second follow-up. The mean $V^{\prime}{ }_{\mathrm{O}_{2} \text { peak }}$ decreased significantly in the group of individuals aged $\geqslant 40$ years over the whole study period, whereas in younger individuals only a slight decrease was observed (figure 4, and tables 2 and 3). In males the mean $V^{\prime}{ }_{\mathrm{O}_{2} \text { peak }}$ decreased from $2507 \mathrm{~mL} \cdot \mathrm{min}^{-1}$ at baseline to 2339 and $2263 \mathrm{~mL} \cdot \mathrm{min}^{-1}$ at the first and second follow-ups, respectively, corresponding to a mean decrease of $8.5 \%$ over the 10 years of follow-up. In females the mean $V^{\prime} \mathrm{O}_{2}$ peak decreased from $1678 \mathrm{~mL} \cdot \mathrm{min}^{-1}$ at baseline to $1573 \mathrm{~mL} \cdot \mathrm{min}^{-1}$ at the first follow-up and afterwards slightly increased to $1614 \mathrm{~mL} \cdot \mathrm{min}^{-1}$ during the second time period. Over the 10 years of follow-up the mean $V^{\prime} \mathrm{O}_{2}$ peak decreased by $3.1 \%$ in females. The mean $V_{\mathrm{O}_{2}}^{\prime} @ \mathrm{AT}$ decreased in all age and sex groups over the

\section{TABLE 1 Baseline characteristics stratified by participation at follow-up}

\begin{tabular}{|c|c|c|}
\hline & Participants & Nonparticipants \\
\hline Subjects & 615 & 1088 \\
\hline Age years & $51(41-60)$ & $53(42-65)$ \\
\hline Male & $317(51.5)$ & $513(47.2)$ \\
\hline \multicolumn{3}{|l|}{ Smoking status } \\
\hline Never-smoker & 272 (44.2) & $473(43.5)$ \\
\hline Ex-smoker & $217(35.3)$ & $333(30.6)$ \\
\hline Current smoker & $126(20.5)$ & $281(25.9)$ \\
\hline BMI $\mathrm{kg} \cdot \mathrm{m}^{-2}$ & $25.9(23.7-28.7)$ & $27.2(24.2-30.8)$ \\
\hline Type 2 diabetes mellitus & $31(5.0)$ & $102(9.4)$ \\
\hline Hypertension & $241(39.2)$ & $556(51.2)$ \\
\hline Myocardial infarction & $10(1.6)$ & 33 (3.0) \\
\hline Stroke & $5(0.8)$ & 20 (1.8) \\
\hline $\mathrm{FEV}_{1} \%$ expected & $100.1(92.2-108.1)$ & 97.2 (86.9-105.6) \\
\hline Maximum power $\%$ expected & 99.3 (88.2-111.5) & $90.8(79.0-104.0)$ \\
\hline$V_{\mathrm{O}_{2} \text { peak }}^{\prime} \%$ expected & 99.9 (89.7-111.0) & $92.2(82.6-104.8)$ \\
\hline$V_{0_{2} \text { QATT } \% \text { expected }}^{\prime}$ & $96.6(85.1-107.6)$ & $92.5(82.8-103.1)$ \\
\hline$V_{\mathrm{E}}^{\prime} / V^{\prime} \mathrm{co}_{2}$ slope \% expected & $99.2(92.1-108.1)$ & $101.4(93.9-110.8)$ \\
\hline Maximum oxygen pulse $\mathrm{mL} \cdot$ beat $^{-1}$ & $102.8(92.8-113.8)$ & $100.0(90.0-112.3)$ \\
\hline
\end{tabular}



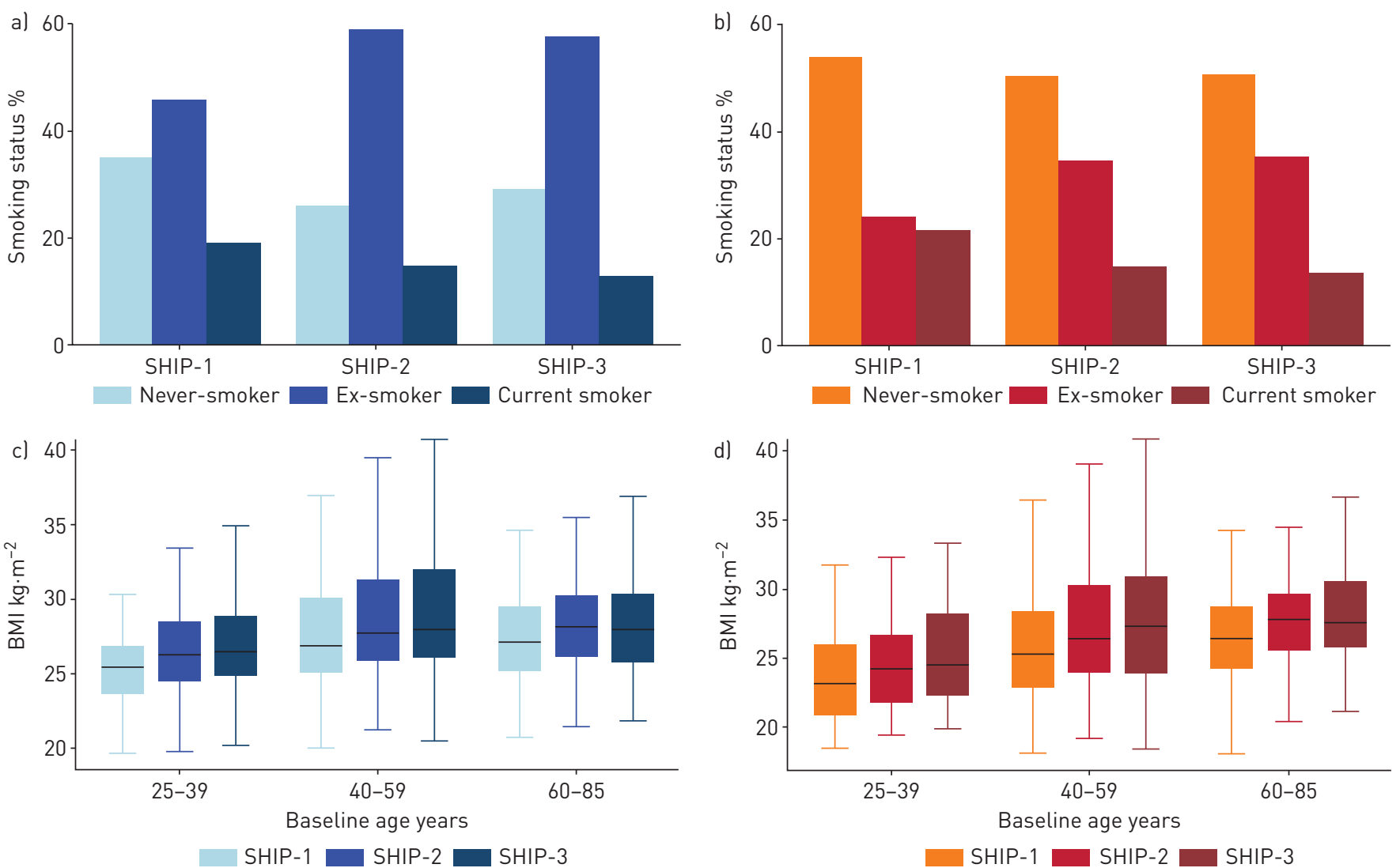

FIGURE 2 Sex-specific development of $a, b)$ smoking status and $c$, d) body mass index (BMI) over the three time-points in the Study of Health in Pomerania (SHIP): $a, c)$ males and b, d) females.

whole study period except for females aged $\geqslant 65$ years (figure 5). Significant decreases were only observed in males aged $\geqslant 60$ years and females aged $<40$ years (table 2 ). Overall, there was a decrease in the mean $V^{\prime} \mathrm{O}_{2} @ A T$ in the first time period, while in the second time period the mean values slightly increased in males and females (table 3). For the $V^{\prime}{ }_{\mathrm{E}} / V^{\prime} \mathrm{CO}_{2}$ slope the mean values increased significantly only in individuals aged $\geqslant 50$ years (figure 6 , and tables 2 and 3 ). While there was an increase of the mean $V^{\prime}{ }_{\mathrm{E}} /$ $V^{\prime} \mathrm{CO}_{2}$ slope during the first follow-up, the mean $V_{\mathrm{E}}^{\prime} / V^{\prime} \mathrm{CO}_{2}$ slope values decreased between the first and second follow-ups in males and females. The mean maximum oxygen pulse decreased significantly in individuals aged $\geqslant 40$ years over the whole study period, while only a slight decrease was observed in individuals aged $<40$ years (figure 7 , and tables 2 and 3 ). In males the mean maximum oxygen pulse decreased in both time periods, whereas in females an increase was observed over the second time period.

The expected $V^{\prime} \mathrm{O}_{2}$ peak levels for the first follow-up as determined from the formula by GLäSER et al. [25] showed a good correlation with the observed $V^{\prime} \mathrm{O}_{2}$ peak levels at the first follow-up $\left(\mathrm{R}^{2}=0.73\right)$ (figure 8). This correlation was slightly higher in males $\left(\mathrm{R}^{2}=0.58\right)$ than in females $\left(\mathrm{R}^{2}=0.50\right)$. The correlation of the expected versus the observed $V^{\prime} \mathrm{O}_{2}$ peak levels for the second follow-up was $\mathrm{R}^{2}=0.60$ (figure 9), and was comparable between males and females (both $\left.\mathrm{R}^{2}=0.45\right)$. Lower $V_{\mathrm{O}_{2} \text { peak }}^{\prime}$ levels $\left(1000-2000 \mathrm{~mL} \cdot \mathrm{min}^{-1}\right.$ ) tended to be underestimated, while higher $V_{\mathrm{O}_{2} \text { peak }}^{\prime}$ levels (2500 (males) or 1500 (females) $\mathrm{mL} \cdot \mathrm{min}^{-1}$ ) tended to be overestimated.

\section{Discussion}

At three different measurement points, 615 individuals $(317$ males and 298 females; age range 25-85 years) were examined with CPET as part of the SHIP epidemiological study. The median observation time was 10.5 years. In summary, males showed a decrease in cardiorespiratory fitness (presented as $V^{\prime} \mathrm{O}_{2}$ peak ) of $-8.5 \%$ over 10 years. Females also showed a decrease in aerobic capacity, but only of $-3.1 \%$ over 10 years. For the first time the decrease in cardiopulmonary performance with age was proven in a large population-based European study.

This phenomenon (i.e. the age-dependent loss of aerobic capacity) has also been demonstrated in current cross-sectional [26] as well as longitudinal studies [21] with CPET. Studies with other functional methods 

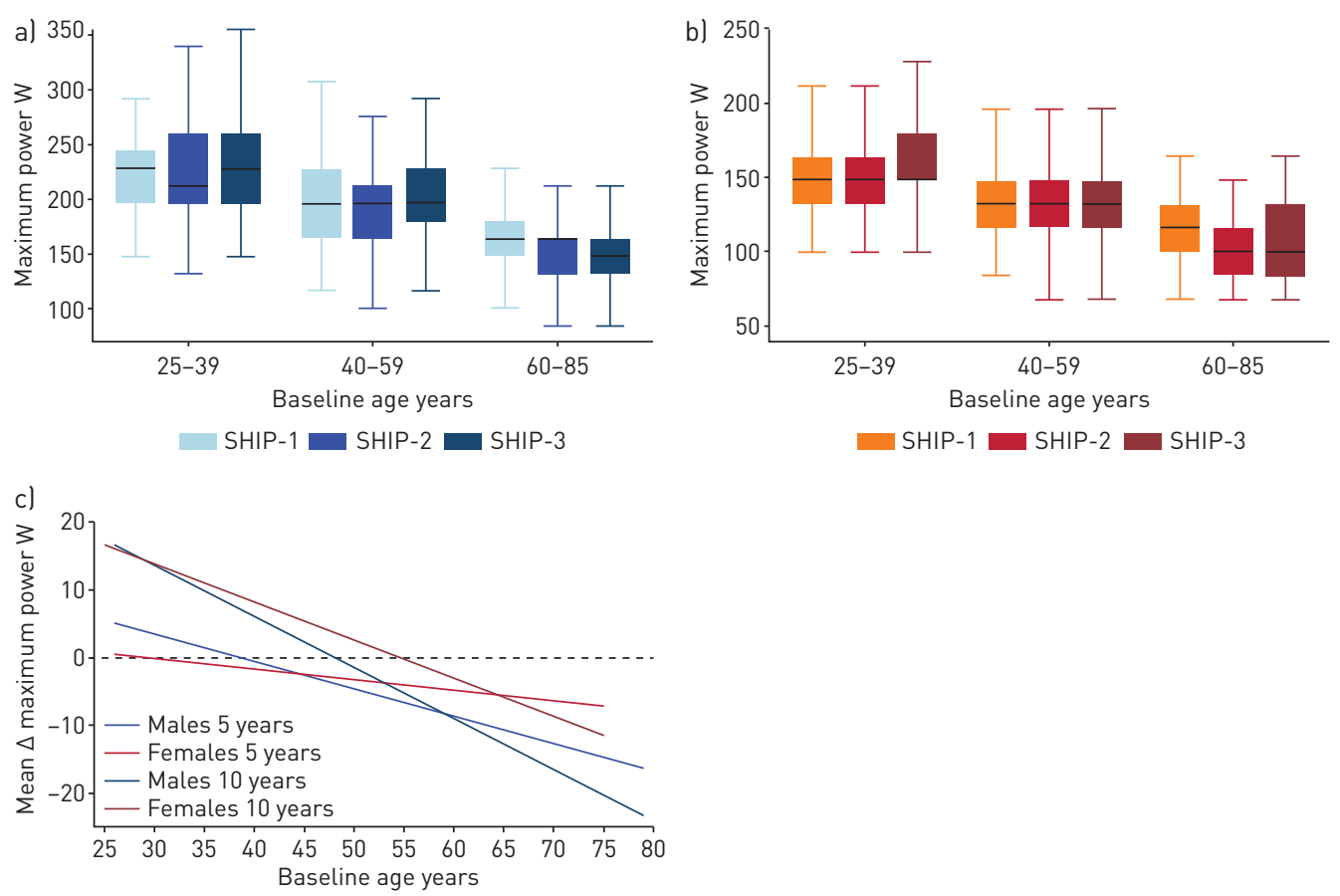

FIGURE 3 Age- and sex-specific changes in maximum power over the three time-points in the Study of Health in Pomerania (SHIP): a) males and b) females. c) Mean change ( $\Delta$ ) of maximum power over 5 and 10 years for both sexes.

(age-specific tests in 1288 individuals [27]) and survey data (study on adult health in Germany 2008-2011 [28]) can also be used to prove this phenomenon.

However, this trend is not only evident in older volunteers, but can also be observed in younger volunteers [29-31]. The data on the age-dependent loss of aerobic capacity were mainly obtained from cross-sectional investigations using linear models. However, longitudinal surveys show a disproportionate decrease in aerobic capacity with increasing age [19]: $8-18 \%$ for the first 10 years and $15-34 \%$ for the following 10 years depending on the amount of training. Our study shows a lower decrease of $V^{\prime} \mathrm{O}_{2}$ peak over 10 years for both males and females in younger age groups (males: 20-39 years, decline $-1.6 \%$; $40-59$ years, decline $-8.1 \%$; $\geqslant 60$ years, decline $-14.9 \%$; females: $20-39$ years, increase $+0.3 \%$; $40-59$ years, decline $-2.2 \%$; $\geqslant 60$ years, decline $-10.3 \%$ ). Data from previous work already indicate that $V_{\mathrm{O}_{2} \text { peak }}$ in females declines less than in males in old age $[12,32]$.

In agreement with other authors, we were able to show statistical significance when comparing calculated

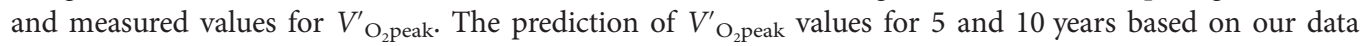

\begin{tabular}{|c|c|c|c|c|c|c|}
\hline & \multicolumn{3}{|c|}{ Males } & \multicolumn{3}{|c|}{ Females } \\
\hline & $20-39$ years & 40-59 years & $>60$ years & $20-39$ years & 40-59 years & $>60$ years \\
\hline Subjects & 76 & 149 & 92 & 65 & 179 & 54 \\
\hline Maximum power $\mathrm{W}$ & $9.1 \pm 28.1 *$ & $-1.7 \pm 28.0$ & $-13.9 \pm 24.1^{*}$ & $9.2 \pm 20.9 *$ & $3.1 \pm 19.2^{*}$ & $-6.6 \pm 17.9 *$ \\
\hline$V_{\mathrm{O}_{2} \text { peak }}^{\prime} \mathrm{mL} \cdot \mathrm{min}^{-1}$ & $-86 \pm 572$ & $-241 \pm 450^{*}$ & $-335 \pm 308^{*}$ & $-10 \pm 300$ & $-49 \pm 251 *$ & $-161 \pm 210^{*}$ \\
\hline$V_{\mathrm{O}_{2}}^{\prime}$ IAAT $\mathrm{mL} \cdot \mathrm{min}^{-1}$ & $-39 \pm 336$ & $-22 \pm 287$ & $-136 \pm 210 *$ & $-64 \pm 180 *$ & $-11 \pm 181$ & $-27 \pm 159$ \\
\hline$V^{\prime}{ }_{E}^{\prime} / V^{\prime}{ }_{\mathrm{CO}_{2}}$ slope & $-0.7 \pm 3.8$ & $0.2 \pm 3.3$ & $1.4 \pm 3.2^{*}$ & $0.1 \pm 2.8$ & $0.1 \pm 3.1$ & $1.6 \pm 3.1 *$ \\
\hline 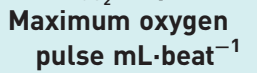 & $-0.16 \pm 2.94$ & $-0.70 \pm 3.22^{*}$ & $-1.46 \pm 2.94^{*}$ & $0.27 \pm 1.74$ & $0.31 \pm 1.83^{*}$ & $-0.39 \pm 2.61$ \\
\hline
\end{tabular}

Data are presented as $\mathrm{n}$ or mean \pm SD. $V^{\prime}{ }_{O_{2} \text { peak }}$ : peak oxygen uptake; $V^{\prime} \mathrm{O}_{2}$ QAT: oxygen uptake at anaerobic threshold; $V_{\mathrm{E}}^{\prime}$ : minute ventilation; $V^{\prime} \mathrm{CO}_{2}$ : carbon dioxide production. ${ }^{*}$ : $\mathrm{p}<0.05$ (t-test for paired data). 
TABLE 3 Percentual differences in cardiopulmonary exercise testing marker levels between baseline and second follow-up (10-year change)

\begin{tabular}{|c|c|c|c|c|c|c|}
\hline & \multicolumn{3}{|c|}{ Males } & \multicolumn{3}{|c|}{ Females } \\
\hline & $20-39$ years & 40-59 years & $>60$ years & 20-39 years & 40-59 years & $>60$ years \\
\hline Subjects & 76 & 149 & 92 & 65 & 179 & 54 \\
\hline Maximum power \% & $5.4 \pm 15.9$ & $0.5 \pm 15.2$ & $-7.8 \pm 14.4$ & $7.0 \pm 14.5$ & $3.5 \pm 15.8$ & $-5.1 \pm 16.2$ \\
\hline$V_{\mathrm{O}_{2} \text { peak }}^{\prime} \%$ & $-1.6 \pm 22.2$ & $-8.1 \pm 17.8$ & $-14.9 \pm 13.4$ & $0.3 \pm 17.4$ & $-2.2 \pm 15.0$ & $-10.3 \pm 13.7$ \\
\hline$V_{O_{2}}^{\prime}$ वAT \% & $-0.6 \pm 23.4$ & $1.9 \pm 29.8$ & $-10.0 \pm 16.8$ & $-4.3 \pm 20.6$ & $0.3 \pm 19.7$ & $-1.9 \pm 17.7$ \\
\hline$V_{\mathrm{E}}^{\prime} / V^{\prime} \mathrm{co}_{2}$ slope $\%$ & $-1.9 \pm 12.8$ & $1.2 \pm 13.9$ & $6.0 \pm 12.7$ & $1.2 \pm 13.0$ & $1.0 \pm 12.6$ & $6.6 \pm 12.2$ \\
\hline $\begin{array}{l}\text { Maximum oxygen } \\
\text { pulse } \%\end{array}$ & $-0.2 \pm 20.0$ & $-3.3 \pm 19.5$ & $-7.8 \pm 17.2$ & $3.4 \pm 16.2$ & $3.8 \pm 17.0$ & $-2.3 \pm 22.2$ \\
\hline
\end{tabular}

Data are presented as $\mathrm{n}$ or mean $\pm \mathrm{SD}$. $V^{\prime} \mathrm{O}_{2}$ peak : peak oxygen uptake; $V_{\mathrm{O}_{2}}$ बAAT: oxygen uptake at anaerobic threshold; $V_{\mathrm{E}}^{\prime}$ : minute ventilation; $V^{\prime} \mathrm{CO}_{2}$ : carbon dioxide production.

shows a clinically acceptable correlation ( $\mathrm{r}=0.6-0.7$ in the whole group). For both sexes, however, higher values of $V^{\prime}{ }_{\mathrm{O}_{2} \text { peak }}$ overestimate future results. This aspect should be considered in the evaluation, especially in the context of clinical decisions.

A variety of factors are cited to explain this reduction, including chronic disease, presence of cardiovascular risk factors and lack of physical activity. Physiological factors influencing aerobic capacity (decrease of maximum heart rate, reduced stroke volume, reduction of peripheral arteriovenous exhaustion, reduction of oxidative capacity of working muscles, etc.) also change with increasing age [33-37]. Recently, the age-related factors influencing aerobic capacity were summarised again [38]. Among other things, it was shown that lung functional parameters are involved in the decline of performance over time. This fact could be proven in 3332 individuals aged 18-35 years when the study was repeated after 20 years (2735 participants) [39]. It was found that a greater decrease in fitness was documented in individuals with a greater decrease in lung function (forced expiratory volume in $1 \mathrm{~s}$ or forced vital capacity).

$V^{\prime} \mathrm{O}_{2}$ peak does not drop in the same way between age groups and between females and males. Possible reasons for sex-specific differences may be weight gain, activity, hormones [40, 41], alcohol consumption [42] as
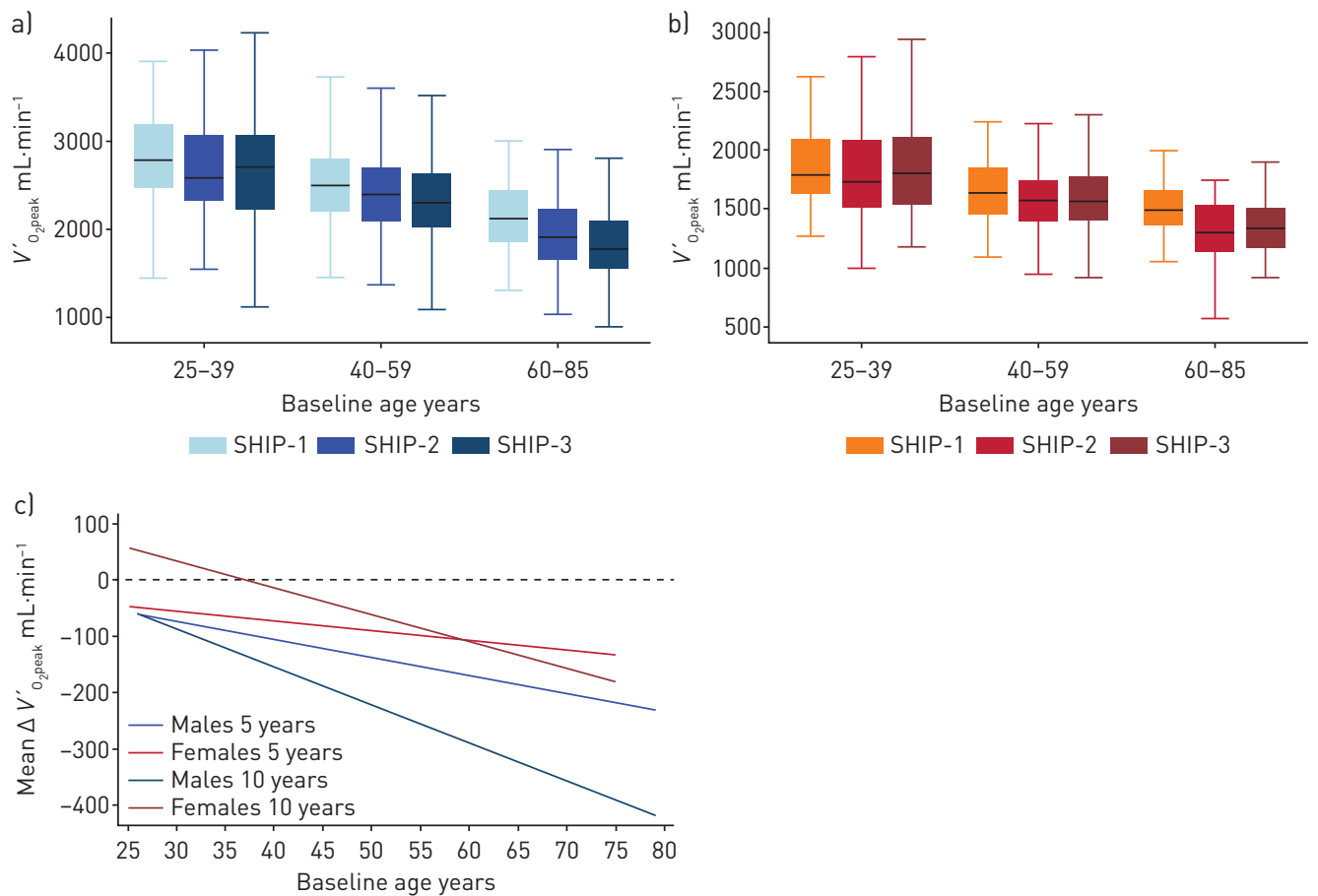

FIGURE 4 Age- and sex-specific changes in peak oxygen uptake $\left(V^{\prime}{ }_{O_{2} \text { peak }}\right)$ over the three time-points in the Study of Health in Pomerania (SHIP): a) males and b) females. c) Mean change $(\Delta)$ of $V_{\mathrm{O}_{2} \text { peak }}$ over 5 and 10 years for both sexes. 

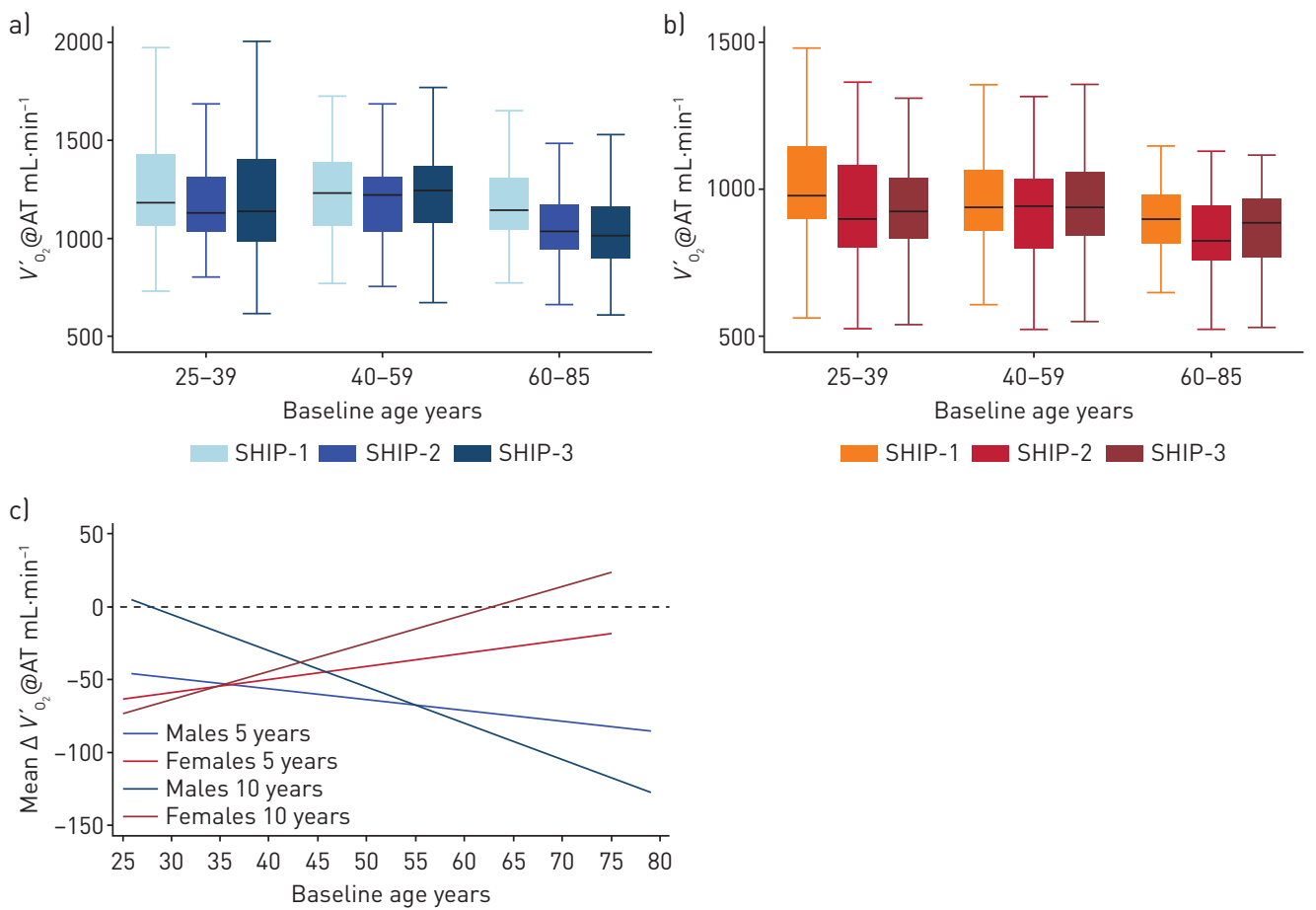

FIGURE 5 Age- and sex-specific changes in oxygen uptake at anaerobic threshold $\left(V^{\prime}{ }_{O_{2}}\right.$ QATT) over the three time-points in the Study of Health in Pomerania (SHIP): al males and b) females. c) Mean change ( $\Delta$ ) of $V^{\prime}{ }_{O_{2}}$ QAAT over 5 and 10 years for both sexes.

well as cardiovascular risk factors and socioeconomic factors [43]. The number of included participants with cardiovascular diseases (myocardial infarction and stroke), except for arterial hypertension, is negligible and therefore does not influence the results of our study.

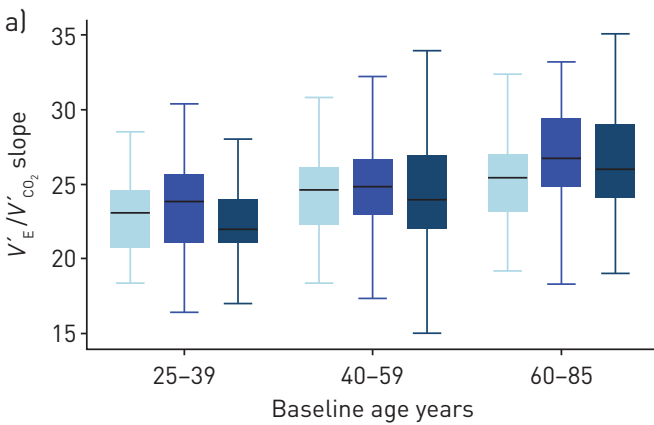

SHIP-1 $=$ SHIP-2 $\square$ SHIP-3

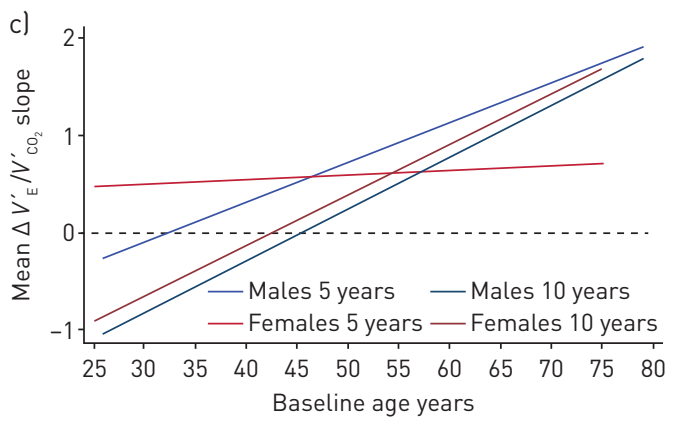

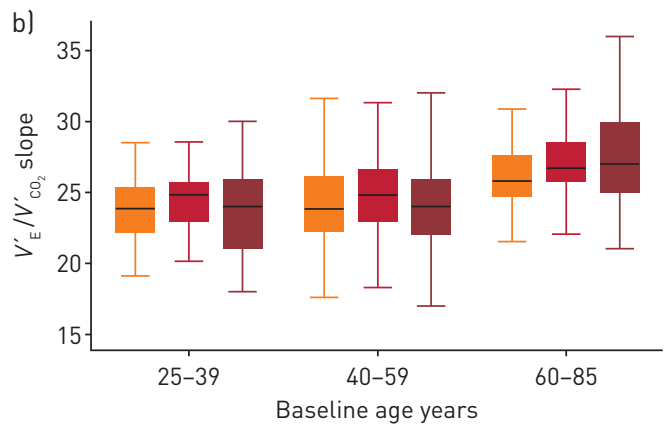

SHIP-1 $\square$ SHIP-2 $\square$ SHIP-3

FIGURE 6 Age- and sex-specific changes in breathing efficiency (minute ventilation $\left(V^{\prime}\right) /$ carbon dioxide production ( $V^{\prime} \mathrm{CO}_{2}$ ) slope) over the three time-points in the Study of Health in Pomerania (SHIP): a) males and b) females. c) Mean change $(\Delta)$ of breathing efficiency over 5 and 10 years for both sexes. 
a)

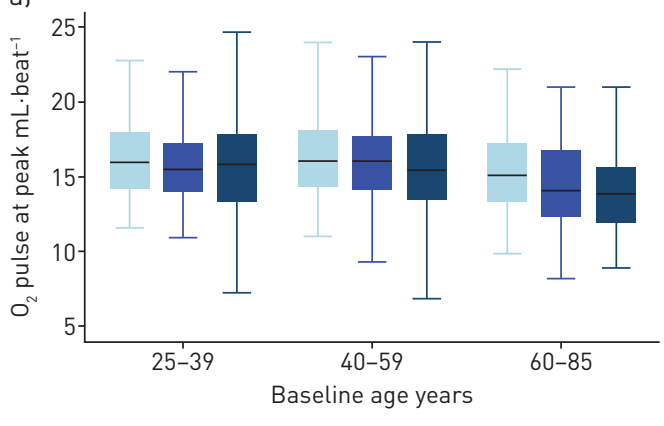

SHIP-1 SHIP-2 $=$ SHIP-3

c)

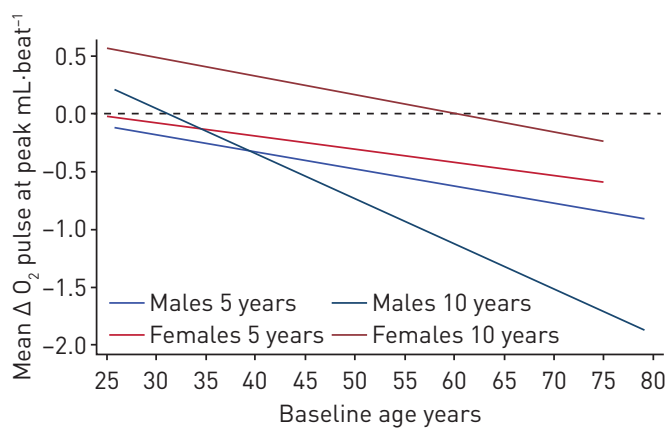

b)

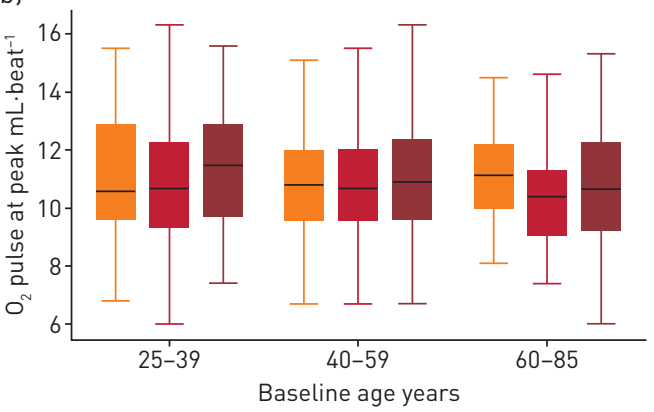

SHIP-1 $=$ SHIP-2 $\square$ SHIP-3

FIGURE 7 Age- and sex-specific changes in peak oxygen pulse over the three time-points in the Study of Health in Pomerania (SHIP): a) males and b) females. c) Mean change ( $\Delta$ ) of peak oxygen pulse over 5 and 10 years for both sexes.

\section{Limitations}

Small deviations of the values are to be assumed by the retrospective introduction of a correction factor with different data collection. In contrast to the compilation of normative values, we included all test individuals in the current analysis, so that those with ventilation disorders, chronic lung or heart diseases
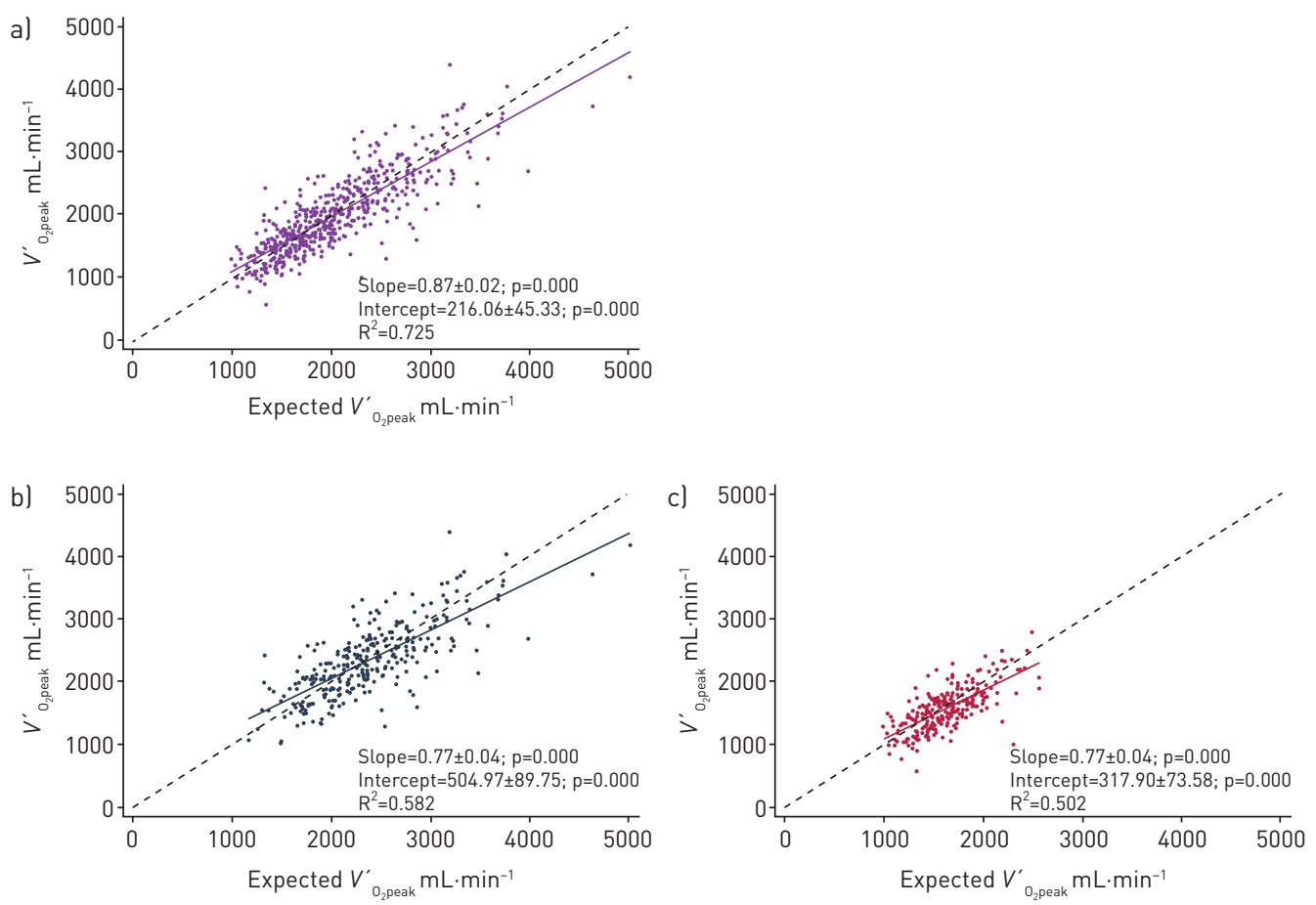

FIGURE 8 Correlation between expected and observed peak oxygen uptake $\left(V^{\prime}{ }_{\mathrm{O}_{2} \text { peak }}\right)$ at the first follow-up (SHIP-2) in the a) total, b) male and c) female population. 

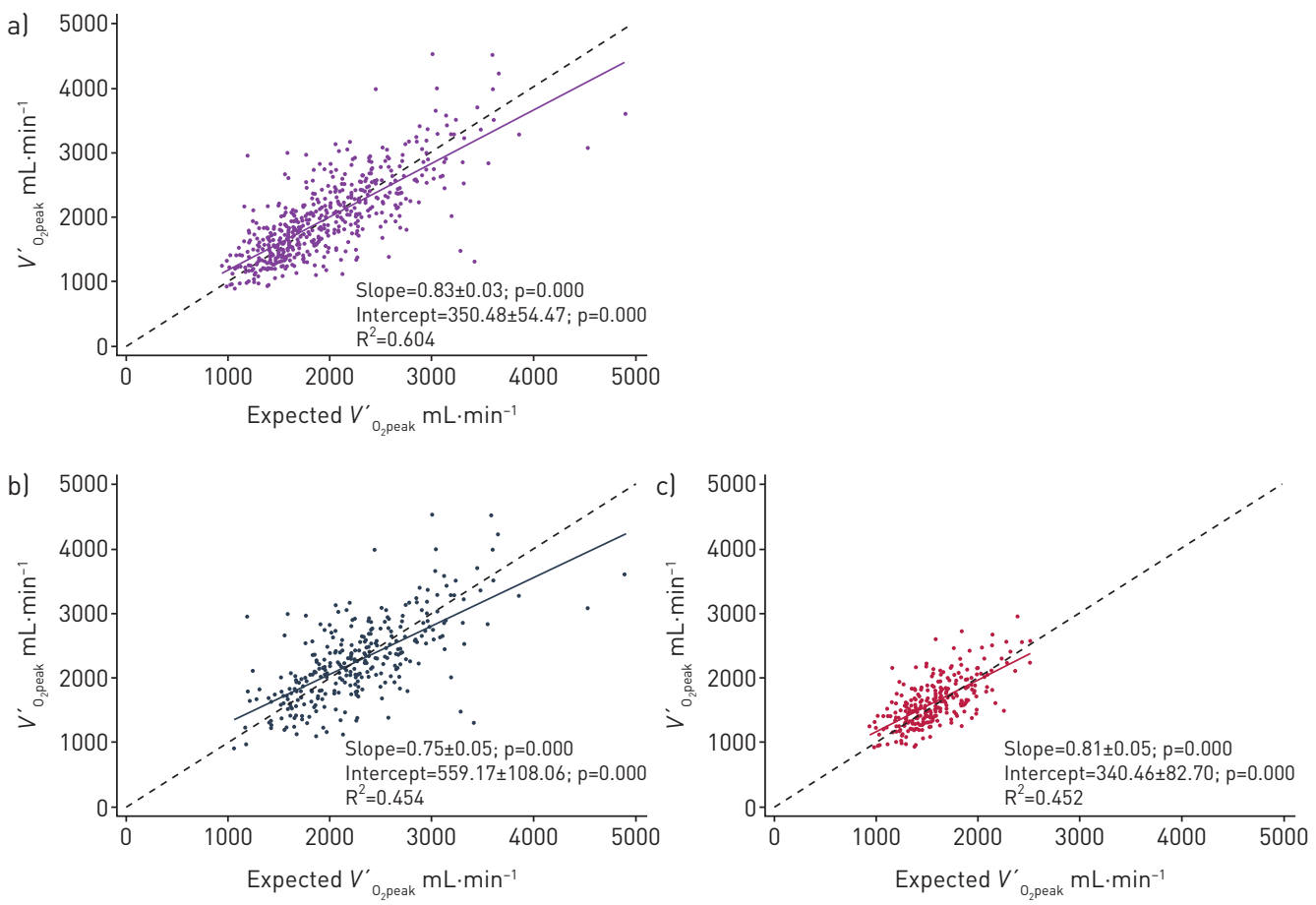

FIGURE 9 Correlation between expected and observed peak oxygen uptake $\left(V^{\prime}{ }_{O_{2} \text { peak }}\right)$ at the second follow-up (SHIP-3) in the a) total, b) male and c) female population.

known from anamnesis and chronic medication (Anatomical Therapeutic Chemical Classification System codes C01, C07, C08 and R03) were also included. We tested all subjects with CPET after a modified Jones protocol on the cycle ergometer, with no differences in the decrease of aerobic capacity with increasing age in the literature (cycle ergometer versus treadmill; meta-analysis by WILSON and TANAKA [15]). Cardiorespiratory fitness shows a high association with the socioeconomic status of subjects [43], which we did not consider in our analyses. The measurement of anaerobic threshold shows an interobserver variability in asymptomatic volunteers [44]. This has to be considered when interpreting the results. The nonlinear models used in the literature to describe the course of CPET data were not used due to the short measurement times. In both older analyses [32] and more recent studies [10], they seem to be an alternative to linear models in the representation of age-dependent $V^{\prime} \mathrm{O}_{2}$ peak progressions from cross-sectional studies.

\section{Conclusions}

In summary, it can be concluded that a decrease in aerobic capacity is concordantly observed with increasing age in cross-sectional and longitudinal studies. In the literature, an exponential decrease is observed over the course of ageing (3-6\% per decade for those aged 20-30 years and $20 \%$ per decade for those aged $\geqslant 70$ years). These data can be confirmed by our longitudinal study over 10 years (considering the selected age groups). As already shown in previous studies, the age-related decrease seems to be somewhat less pronounced in females.

Acknowledgements: We would like to thank all individuals who participated in the Study of Health in Pomerania as well as the "SHIP" staff.

Author contributions: All authors made a substantial contribution to the conception and design of the study, analysis and interpretation of the data, and drafting the article and revising it critically for important intellectual content, and gave final approval of the version to be published.

Support statement: The work is part of the Community Medicine Research net (CMR) of the University of Greifswald, Germany, which is funded by the Federal Ministry of Education and Research (grant numbers ZZ9603, 01ZZ0103 and 01ZZ0403), Competence Network Asthma/COPD (FKZ 01GI0881-0888), the Ministry of Cultural Affairs, and the Social Ministry of the Federal State of Mecklenburg-West Pomerania. The CMR encompasses several research projects which are sharing data of the population-based Study of Health in Pomerania (www.ship.community-medicine.de) Funding information for this article has been deposited with the Crossref Funder Registry. 
Conflict of interest: B. Stubbe has nothing to disclose. T. Ittermann has nothing to disclose. S. Kaczmarek has nothing to disclose. A. Obst has nothing to disclose. M. Bahls has nothing to disclose. T. Bollmann has nothing to disclose. S. Gläser reports personal fees from Boehringer Ingelheim, Roche Pharma, Berlin-Chemie, PneumRX, Pulmonx, Actelion Pharma and Bayer Healthcare; and grants and personal fees from Novartis Pharma, all outside the submitted work. H. Völzke has nothing to disclose. M. Dörr has nothing to disclose. R. Ewert has nothing to disclose.

\section{References}

1 Guazzi M, Arena R, Halle M, et al. 2016 focused update: clinical recommendations for cardiopulmonary exercise testing data assessment in specific patient populations. Circulation 2016; 133: e694-e711.

2 Imboden MT, Harber MP, Whaley MH, et al. Cardiorespiratory fitness and mortality in healthy men and women. J Am Coll Cardiol 2018; 72: 2283-2292.

3 Kodama S, Saito K, Tanaka S, et al. Cardiorespiratory fitness as a quantitative predictor of all-cause mortality and cardiovascular events in healthy men and women: a meta-analysis. JAMA 2009; 301: 2024-2035.

4 Bahls M, Gross S, Baumeister SE, et al. Association of domain-specific physical activity and cardiorespiratory fitness with all-cause and cause-specific mortality in two population-based cohort studies. Sci Rep 2018; 8: 16066.

5 Kunutsor SK, Kurl S, Khan $\mathrm{H}$, et al. Oxygen uptake at aerobic threshold is inversely associated with fatal cardiovascular and all-cause mortality events. Ann Med 2017; 49: 698-709.

6 Al-Mallah MH, Qureshi WT, Keteyian SJ, et al. Racial differences in the prognostic value of cardiorespiratory fitness (results from the Henry Ford Exercise Testing Project). Am J Cardiol 2016; 117: 1449-1454.

7 Aspenes ST, Nilsen TI, Skaug EA, et al. Peak oxygen uptake and cardiovascular risk factors in 4631 healthy women and men. Med Sci Sports Exerc 2011; 43: 1465-1473.

8 Loe H, Steinshamn S, Wisloff U. Cardio-respiratory reference data in 4631 healthy men and women 20-90 years: the HUNT 3 fitness study. PLoS One 2014; 9: e113884.

9 Rapp D, Scharhag J, Wagenpfeil S, et al. Reference values for peak oxygen uptake: cross-sectional analysis of cycle ergometry-based cardiopulmonary exercise tests of 10090 adult German volunteers from the Prevention First Registry. BMJ Open 2018; 8: e018697.

10 Mylius CF, Krijnen WP, van der Schans CP, et al. Peak oxygen uptake reference values for cycle ergometry for the healthy Dutch population: data from the LowLands Fitness Registry. ERJ Open Res 2019; 5: 00056-2018.

11 Edvardsen E, Hansen BH, Holme IM, et al. Reference values for cardiorespiratory response and fitness on the treadmill in a 20- to 85-year-old population. Chest 2013; 144: 241-248.

12 Paterson DH, Cunningham DA, Koval JJ, et al. Aerobic fitness in a population of independently living men and women aged 55-86 years. Med Sci Sports Exerc 1999; 31: 1813-1820.

13 Kaminsky LA, Imboden MT, Arena R, et al. Reference standards for cardiorespiratory fitness measured with cardiopulmonary exercise testing using cycle ergometry: data from the Fitness Registry and the Importance of Exercise National Database (FRIEND) Registry. Mayo Clin Proc 2017; 92: 228-233.

14 Hawkins S, Wiswell R. Rate and mechanism of maximal oxygen consumption decline with aging: implications for exercise training. Sports Med 2003; 33: 877-888.

15 Wilson TM, Tanaka H. Meta-analysis of the age-associated decline in maximal aerobic capacity in men: relation to training status. Am J Physiol Heart Circ Physiol 2000; 278: H829-H834.

16 Fitzgerald MD, Tanaka H, Tran ZV, et al. Age-related declines in maximal aerobic capacity in regularly exercising vs. sedentary women: a meta-analysis. J Appl Physiol 1997; 83: 160-165.

17 Schneider J. Age dependency of oxygen uptake and related parameters in exercise testing: an expert opinion on reference values suitable for adults. Lung 2013; 191: 449-458.

18 Stathokostas L, Jacob-Johnson S, Petrella RJ, et al. Longitudinal changes in aerobic power in older men and women. J Appl Physiol 2004; 97: 781-789.

19 Fleg JL, Morrell CH, Bos AG, et al. Accelerated longitudinal decline of aerobic capacity in healthy older adults. Circulation 2005; 112: 674-682.

20 Hollenberg M, Yang J, Haight TJ, et al. Longitudinal changes in aerobic capacity: implications for concepts of aging. J Gerontol A Biol Sci Med Sci 2006; 61: 851-858.

21 Laukkanen JA, Zaccardi F, Khan $\mathrm{H}$, et al. Long-term change in cardiorespiratory fitness and all-cause mortality: a population-based follow-up study. Mayo Clin Proc 2016; 91: 1183-1188.

22 Volzke H, Alte D, Schmidt CO, et al. Cohort profile: the Study of Health in Pomerania. Int J Epidemiol 2011; 40: 294-307.

23 Ewert R, Ittermann T, Bollmann T, et al. Pneumologisch relevante Daten aus der "Study of Health in Pomerania" (SHIP) - eine Übersicht zu den Kohorten, Methoden und ersten Ergebnissen. [Lung health data of the Study of Health in Pomerania - a review of samples, methods and first results.] Pneumologie 2017; 71: 17-35.

24 Koch B, Schaper C, Ittermann $\mathrm{T}$, et al. Reference values for cardiopulmonary exercise testing in healthy volunteers: the SHIP study. Eur Respir J 2009; 33: 389-397.

25 Glaser S, Ittermann T, Schaper C, et al. Referenzwerte für die Spiroergometrie - Ergebnisse der Study of Health in Pomerania (SHIP). [The Study of Health in Pomerania (SHIP) reference values for cardiopulmonary exercise testing.] Pneumologie 2013; 67: 58-63.

26 Stensvold D, Bucher Sandbakk S, Viken H, et al. Cardiorespiratory reference data in older adults: the Generation 100 Study. Med Sci Sports Exerc 2017; 49: 2206-2215.

27 Milanovic Z, Pantelic S, Trajkovic N, et al. Age-related decrease in physical activity and functional fitness among elderly men and women. Clin Interv Aging 2013; 8: 549-556.

28 Krug S JS, Mensink GBM, Müters S, et al. Results of the German Health Interview and Examination Survey for Adults (DEGS1). Bundesgesundheitsblatt 2013; 56: 765-771.

29 Leyk D, Ruther T, Witzki A, et al. Physical fitness, weight, smoking, and exercise patterns in young adults. Dtsch Arztebl Int 2012; 109: 737-745.

30 Ekblom O, Oddsson K, Ekblom B. Health-related fitness in Swedish adolescents between 1987 and 2001. Acto Paediatr 2004; 93: 681-686.

31 Hulkkonen J, Aatola H, Palve K, et al. Determinants of exercise peak arterial blood pressure, circulatory power, and exercise cardiac power in a population based sample of Finnish male and female aged 30 to 47 years: the Cardiovascular Risk in Young Finns Study. BMC Cardiovasc Disord 2014; 14: 35. 
Cunningham DA, Paterson DH, Koval JJ, et al. A model of oxygen transport capacity changes for independently living older men and women. Can J Appl Physiol 1997; 22: 439-453.

33 Betik AC, Hepple RT. Determinants of $\mathrm{VO}_{2 \text { max }}$ decline with aging: an integrated perspective. Appl Physiol Nutr Metab 2008; 33: 130-140.

34 Russ DW, Kent-Braun JA. Is skeletal muscle oxidative capacity decreased in old age? Sports Med 2004; 34: 221-229.

35 Carrick-Ranson G, Hastings JL, Bhella PS, et al. The effect of age-related differences in body size and composition on cardiovascular determinants of $\mathrm{VO}_{2} \mathrm{max}$. J Gerontol A Biol Sci Med Sci 2013; 68: 608-616.

36 Limacher MC. Aging and cardiac function: influence of exercise. South Med J 1994; 87: S13-S16.

37 Bryant BA, Limacher MC. Exercise testing in selected patient groups. Women, the elderly, and the asymptomatic. Prim Care 1994; 21: 517-534.

38 Roman MA, Rossiter HB, Casaburi R. Exercise, ageing and the lung. Eur Respir J 2016; 48: 1471-1486.

39 Benck LR, Cuttica MJ, Colangelo LA, et al. Association between cardiorespiratory fitness and lung health from young adulthood to middle age. Am J Respir Crit Care Med 2017; 195: 1236-1243.

40 Kerstholt N, Ewert R, Nauck M, et al. Association of circulating irisin and cardiopulmonary exercise capacity in healthy volunteers: results of the Study of Health in Pomerania. BMC Pulm Med 2015; 15: 41.

41 Glaser S, Friedrich N, Ewert R, et al. Association of circulating IGF-I and IGFBP-3 concentrations and exercise capacity in healthy volunteers: results of the Study of Health in Pomerania. Growth Horm IGF Res 2010; 20: 404-410.

42 Baumeister SE, Finger JD, Glaser S, et al. Alcohol consumption and cardiorespiratory fitness in five population-based studies. Eur J Prev Cardiol 2018; 25: 164-172.

43 Ombrellaro KJ, Perumal N, Zeiher J, et al. Socioeconomic correlates and determinants of cardiorespiratory fitness in the general adult population: a systematic review and meta-analysis. Sports Med Open 2018; 4: 25.

44 Kaczmarek S, Habedank D, Obst A, et al. Interobserver variability of ventilatory anaerobic threshold in asymptomatic volunteers. Multidiscip Respir Med 2019; 14: 20. 